\title{
Your wish is my command! Influence of symbolic modelling on preschool children's delay of gratification
}

Sahlia Kumst, Damian Scarf

Children's ability to delay gratification is correlated with a range of positive outcomes in adulthood, showing the potential impact of helping young children increase their competence in this area. This study investigated the influence of symbolic models on 3year-old children's self-control. Eighty-three children were randomly assigned to one of three modelling conditions: personal story-telling, impersonal story-telling, and control. Children were tested on the delay-of-gratification maintenance paradigm both before and after being exposed to a symbolic model or control condition. Repeated measures ANOVA revealed no significant differences between the two story-telling groups and the control group, indicating that the symbolic models did not influence children's ability to delay gratification. A serendipitous finding showed a positive relationship between children's ability to wait and their production and accurate use of temporal terms, which was more pronounced in girls than boys. This finding may be an indication that a higher temporal vocabulary is linked to a continuous representation of the self in time, facilitating children's representation of the future-self receiving a larger reward than what the present-self could receive. 
2 Your wish is my command! Influence of Symbolic Modelling on Preschool Children's Delay of Gratification. 3

9 Correspondence:

10 Damian Scarf

11 Address: P.O. Box 56

129054 Dunedin

13 New Zealand

14 Email: damian@psy.otago.ac.nz

15 Telephone: +6434797636

16 Fax: +6434798335 
19 Children's ability to delay gratification is correlated with a range of positive outcomes in adulthood. The current study 20 investigated whether symbolic models could be used to improve 3-year-old children's performance on the delay-of21 gratification maintenance paradigm. Eighty-three children were randomly assigned to one of three modelling conditions: 22 personal story-telling, impersonal story-telling, and control. Children were tested on the delay-of-gratification maintenance 23 paradigm both before and after being exposed to either a symbolic model or control condition. Repeated measures ANOVA 24 revealed no significant differences between the two story-telling groups and the control group, indicating that the symbolic 25 models did not influence children's ability to delay gratification. However, we did find a positive relationship between 26 children's ability to wait and their production and accurate use of temporal terms, which was more pronounced in girls than

27 boys. This finding may be an indication that a higher temporal vocabulary is related to children's ability to form continuous 28 representation of the self in time, facilitating children's representation of the future-self receiving a larger reward than what 29 the present-self could receive.

30 Keywords: Delay of gratification, Maintenance paradigm, Symbolic modelling, Story books, Pre-school children 
The ability to forgo an immediate reward and wait for a larger reward, delayed in time, is known as delay of gratification (Mischel \& Underwood 1974). In pre-school children, delay of gratification provides a simple measure of selfcontrol and self-regulation. Interestingly, pre-school children's ability to delay gratification is predictive of a range of life outcomes that extend well beyond the pre-school years. For example, pre-school children that are better able to cope with a delay cope better in stressful and frustrating situations during adolescence (Mischel et al. 1988; Shoda et al. 1990). Further, Casey and colleagues (2011) demonstrated that children who have difficulty delaying gratification at age 4 have difficulty resisting temptations and displaying cognitive control in adulthood. With respect to life outcomes, difficulty in delaying gratification in childhood is correlated with poorer cardiovascular, respiratory, dental and sexual health (Moffitt et al. 2011), a higher body mass index (Schlam et al. 2013), increased aggression (Ayduk et al. 2007), criminal offenses (Moffitt et al. 2011), substance abuse (Madden et al. 1997), and lower self-esteem, academic achievement (Li-Grining 2007; Mischel et al. 1989; Wulfert et al. 2002) and social skills (McIntyre et al. 2006) in adulthood. Given its predictive nature, improving children's ability to delay gratification has a number of potential benefits.

Metcalfe and Mischel (1999) proposed a theoretical framework to explain why some children are capable of delaying gratification while others are not. In this framework, two distinct but interacting systems underlie children's ability to delay. The "cool" or cognitive system is responsible for thought and reflection. This system allows the individual to reflect on the options at hand and select the one that best serves their long-term interests. The "hot" or emotional system is characterized by quick emotional processing and satisfying immediate needs. For example, in the delay-of-gratification maintenance paradigm (Mischel et al. 1989), the child is presented with an object they desire (e.g., a marshmallow), which is highly salient and activates the "hot" system, pushing children toward the immediately gratifying response of grabbing the marshmallow. On the other hand, the "cool" system allows children to reflect on the fact that, if they want to gain an even more desirable outcome (e.g., two marshmallows), they must wait. The balance between the "hot" and "cool" systems is thought to be an intrinsic trait, responsible for children's differential performance on the delay-of-gratification tasks (Metcalfe \& Mischel 1999).

Importantly, however, numerous external factors can be used to either increase or decrease children's ability to delay gratification. For example, increasing a child's attention to the salient attributes of the immediate reward, such as looking directly at the reward or talking about it, results in shorter wait times (Mauro \& Harris 2000; Mischel \& Underwood 1974; Putnam et al. 2002), while distraction techniques such as covering up the reward or thinking of the reward in a non-consummatory fashion results in longer waiting times (Sethi et al. 2000). In addition to salience and attentional strategies, parental style and attachment also predict delay behaviour. Children of parents with an authoritarian style tend to delay gratification while those with permissive parents do not (Mauro \& Harris 2000). Maternal regulatory strategies, such as distraction, reasoning, bargaining, indirect and direct commands, also impact children's performance, with distraction being the most effective strategy (Putnam et al. 2002). 
and fantasy rehearsal. Bandura and McClelland's (1977) social learning theory posits that behaviour is learnt from the environment through observation. Models (e.g., parents) explicitly convey how tasks should be performed and, as a result, shorten how long it takes children to learn a task or skill. The model may be a live individual demonstrating a behaviour, a verbal description or explanation of a behaviour, or symbolic (i.e., the behaviour is modelled in a book, on television, or other media) (Bandura \& McClelland 1977). A number of factors contribute to the influence of models on children's behaviour. For example, the more the child identifies with the model, the more likely they are to reproduce the behaviour (Bandura \& McClelland 1977).

Bandura and Mischel (1965) demonstrate the influence models have on 4- and 5-year-old children's performance on the delay-of-gratification task. After being tested on the task, children either observed an adult enact the opposite decision to what the child had just made or listened to a verbal description of the behaviour. For example, if the child chose to wait the adult did not wait. Following this manipulation, children were immediately re-tested and again after a 4- to 5week delay. Tellingly, children who at first delayed gratification shifted to choosing the immediate reward and children who initially chose the immediate reward tended to favour waiting for the delayed reward. Of note is the fact that the live model and the verbal model had a comparable impact on the immediate test, but only the live model influenced children's behaviour at the 4- or 5-week follow-up.

An attribute of symbolic models is that they can take the form of a story, which is attractive for young children who regularly have story books read to them. Illustrated stories are particularly effective with preschool children because they are visually interesting and easily memorized (Strayhorn Jr 1988). Picture books have the potential to provide children with information about the world, allowing them to acquire additional knowledge to what they learn by personal experience (Heath et al. 2014). For example, picture books influence children's healthy eating behaviour (de Droog et al. 2014; Heath et al. 2014) and facilitate the acquisition of novel words and their extension to real objects, especially when these objects are realistically depicted in the picture book (Ganea et al. 2008; Tare et al. 2010). Further, 18- to 30-month-old children can learn simple novel actions through picture book readings (Simcock \& DeLoache 2006).

In addition to the pictures displayed, the behaviour of characters or the comments they make can also be used to show children how to achieve specific goals or acquire coping strategies (Strayhorn Jr 1988). Narrations in story books may provide information about resolving problems successfully and indicate the personal qualities and behaviours that are associated with the achievement of a goal. Therefore, story books may foster messages coming directly from caregivers about which beliefs and behaviours are fundamental for success (Suprawati et al. 2014). Through repeating the story, as children often like to do, the child is free to imaginatively experience the behaviour or cognitive pattern of the model and rehearses it. Repetition may also help with abstraction, aiding children's ability to transfer the behaviour to situations beyond those conveyed in the story (Strayhorn Jr 1988). It is known that the effectiveness of modelling can be promoted by presenting a model who encounters similar difficulties to the child, and who models how to overcome these difficulties through self-directed instruction (Meichenbaum 1971). Children who have trouble in activities similar to those the model experiences are more likely to imitate the model than children who are successful in those activities (Gelfand 1962) and 
101

102

103

104

105

106

107

108

109

110

111

112

113

114

115

116

117

118

119

120

121

122

123

124

125

126

127

128

129

130

131

132

models whose behaviour is rewarded are more likely to be imitated than models whose behaviour is punished (Bandura 1965).

Although the potential influence of symbolic models has been discussed extensively in the literature, few studies have actually investigated the potential impact of symbolic models on children's ability to delay gratification. In one of the few studies, Lee, Lan, Wang, and Chiu (2008) investigated whether preschool children's ability to delay gratification could be influenced by either explicitly labelling the children as being very patient individuals, saying that they had heard they were able to concentrate well and do boring things for a long period of time, or by reading a story to them, in which an impulsive child received only one gift whereas a patient child received two gifts. The children who were labelled as patient delayed significantly longer than children in the control group, demonstrating the power of self-perception and priming. However, no statistically significant differences were found between the story-telling group and the control group, although they did delay one minute longer on average than controls (Lee et al. 2008). The limited effect of story-telling in this study could be due to the fact that the story was only read once, and to a full classroom. It is an open question as to whether reading the story to children individually, and on multiple occasions, would produce more promising results.

The current study was designed to examine the effects of both personal and impersonal story-telling on 3-year- old children's ability to delay gratification. Children were given story books to take home, that included either a personal or impersonal story, and parents were asked to read the story books to their children for approximately 1 week. Critically, children's ability to delay gratification was assessed both before and after the story book intervention. We hypothesized that that children in the personal and impersonal story-telling conditions would delay gratification longer than those in the control condition, because in the story, models demonstrated that waiting will be rewarded with a large gift and being impatient leads to a small gift. Further, it was predicted that children in the personal story-telling condition, whose names were included in the story, would wait longer than children in the impersonal story-telling condition. This second prediction was based on previous findings demonstrating that perceiving oneself as similar to the model enhances reproduction of the modelled behaviour and that observing similar others succeed reinforces one's belief in one's own capabilities (Bandura \& McClelland 1977; Schunk 1987).

\section{Method}

\section{Participants}

A total of 83 (37 boys and 50 girls) 3-year-old children participated in the present study (Mean age: 34 months 20 days, Range: 30 months 17 days to 39 months 27 days). Three additional parents withdrew their children from the study after participating in the pre-test due to family reasons. One child was excluded from the sample because their postintervention test took place one month after the pre-intervention test, due to unforeseen delays. All children were recruited from the Early Learning Project database of parents who had expressed interest in taking part in research at the University of Otago and participated with written consent from their parents. At the end of the experimental session, children received

PeerJ reviewing PDF | (v2014:12:3614:1:1:NEW 25 Jan 2015) 
133 a small gift and parents received a patrol voucher to compensate them for their travel costs to and from the laboratory. This 134 study was approved by the Human Ethics Committee at the University of Otago (Approval Number: 11/106).

\section{Materials}

The experimental room contained a sofa and a child's table with four different coloured chairs. Parents were asked to remain seated on the sofa behind the child, who sat at the table facing away from them. On the table in front of the child were two closed gift boxes of different sizes: the small gift box measured $8 \mathrm{~cm}$ in width and $6 \mathrm{~cm}$ in height and the large gift box $16 \mathrm{~cm}$ in width and $13 \mathrm{~cm}$ in height. Each gift box could be opened by lifting the lid, to which an ornamental ribbon was attached. Gift boxes were chosen over wrapped gifts because taking a peak under a lid is easier than unwrapping a gift, presumably making it more tempting for children. The small gift box contained five stickers and the large gift box contained either a male or female Playmobil ${ }^{\circledR}$ figure.

Six versions of the picture book were created. The images in the picture book were the same for all conditions, except that girls saw princesses and fairy godmothers, while boys saw princes and wizards. Only the content of the story changed from one condition to the next. In the control story, two princes or princesses go for a walk in the forest, where they meet a benevolent magical figure (wizard or fairy godmother). One child is a bit hungry and is given a lollipop, while the other child receives a toy that they had supposedly lost in the forest and which the magical figure had found. In contrast to the control story, the personal- and impersonal modelling stories deliberately model a delay-of-gratification scenario. In these stories, the princes or princesses come across the magical figure and are offered a choice between receiving a small gift immediately or a larger gift later. One child is impatient while the other is willing to wait. The impatient child only receives a lollipop while the patient child receives a teddy bear (girls) or toy car (boys) after waiting for the magical figure to return with more 'present potion' or 'magic present dust'. The only difference between the personal- and impersonal modelling stories was that the patient prince or princess was named after the participant in the personal condition. All parents were asked to read the assigned story book to their child, every night before bedtime, for 1 week.

\section{Procedure}

Families were contacted by telephone and were given a description of the experiment. When parents agreed for their child to participate in the study, the child was randomly assigned to one of three conditions: personal story-telling $(n=$ 27), impersonal story-telling $(n=27)$ and control story-telling $(n=29)$.

Behavioural measures.

Pre-intervention assessment. In the initial phase of the experiment the children's ability to delay gratification was assessed using the maintenance paradigm (Mischel 2014; Mischel et al. 1989). This paradigm consists of a single trial where the total amount of time that the child is willing to wait for a reward is measured.

Children were tested individually in a quiet room by a female experimenter. The experimenter brought the participant to the laboratory where the child was given 5 minutes to get accustomed to the room and its decorations. During 
165

166

167

168

169

170

171

172

173

174

175

176

177

178

179

180

181

182

183

184

185

186

187

188

189

190

191

192

193

194

195

196

this time the parent read and signed the consent form and completed a questionnaire. The experimenter then seated the child at the table, facing away from their parent. Children's behaviour was filmed by a camera that was set up in the room. Parents stayed in the room with the child during the experiment and were asked not to distract the child by asking questions, directing the child's attention to things in the environment, or making comments concerning the task.

The children were shown both gift boxes, and were told that if they did not peek into the little gift box until the experimenter came back into the room (15 minutes) that they could keep what was in the little gift and would additionally receive what was in the larger gift box. The time started when the experimenter left the room, taking the larger gift with them. The dependent measure was the number of minutes between the moment the experimenter closed the door and the moment the child opened the lid of the gift box or the end of the specified 15 minute period. Upon completion of the task, the children were given their assigned story book and parents received instructions to read the book to their children once a day for 1 week.

Post-intervention assessment. One week later, all children returned to the laboratory for a second test of their ability to delay gratification. The same procedure was used as in the pre-intervention.

\section{Cognitive measures.}

Parents filled out a questionnaire created by Busby Grant and Suddendorf (2011) assessing children's production and accurate use of temporal terms. The questionnaire is composed of a list of 18 temporal terms and phrases. Parents are asked to indicate whether their child uses these terms by answering with yes or no, and to rate how frequently and accurately their child uses these terms on a five-point Likert scale ( $1=$ 'never', $2=$ 'occasionally', $3=$ 'sometimes', $4=$ 'often', 5 = 'always'). Parents completed the questionnaire prior to children being assessed.

Results

The performance of children in each condition is shown in Table 1. Across the three groups, 30/83 children (Personal story: 8/27, Impersonal story: 10/27, Control: 12/29) waited the full 15 minutes at pre-test. With these children included, the average time children were willing to wait at pre-test was 7.81 minutes (Personal story: 7.94 min., Impersonal story: $7.18 \mathrm{~min}$, Control: $8.29 \mathrm{~min}$.). Importantly, the average time children were willing to wait did not differ across the three conditions at pre-test, $F(2,80)=.218, p=.804$.

To assess the potential impact of symbolic modelling, we conducted a repeated-measures Analysis of Variance (ANOVA) with Condition (2: Personal story-telling vs. Impersonal story-telling vs. Control) and Gender (2: Girls vs. Boys) as factors. The analysis revealed no significant effect of Session, $F(1,76)=.890, p=.348$, suggesting the length of time children were willing to wait did not differ between the pre- and post-intervention phases. Further, there was no Session by Condition interaction, $F(2,76)=.316, p=.730$, suggesting the absence of any change between pre- and post-intervention was true for all three conditions. Finally, there was no Session by Condition by Gender interaction, $F(2,76)=.104, p=$ .902 , suggesting the absence of any change between pre- and post-intervention, for any condition, was true for both boys 
and girls. Overall, this shows that the modelled behaviour in the fairy tales did not lead to a statistically significant improvement in children's self-control.

\section{TABLE 1 ABOUT HERE}

The absence of any change between the pre- and post-intervention sessions could be due to a ceiling effect as 30 (36\%) children waited the 15 minutes at pre-test and consequently could not further improve at post-test. Therefore, a second repeated-measures ANOVA was conducted with these children excluded. A significant effect of Session was found, $F(1,47)=4.29, p=.044$, suggesting a change in the length of time children were willing to wait between pre- and postintervention, but no interaction was found between Session and Condition, $F(2,47)=.686, p=.509$, indicating that this change between pre- and post-intervention was present in all conditions. Finally, no Session by Gender by Condition interaction was found, $F(2,47)=13.64, p=.452$, suggesting the change between pre- and post-intervention was observed in all conditions, for both girls and boys. The fact that children were willing to wait longer during the post-intervention test may be due to the children being more comfortable with the experimenter and the context of the experiment. Since this improvement in waiting time was observed across all conditions we can once again conclude that symbolic modelling did not influence children's ability to delay gratification (Table 2).

\section{TABLE 2 ABOUT HERE}

Out of exploratory interest we investigated whether children's use of temporal terms was related to their ability to delay gratification. We correlated children's mean waiting time (across pre- and post-intervention tests) with scores obtained on the three questions in the temporal questionnaire. The number of temporal terms used by children was significantly correlated with their ability to delay gratification, $n=83, r=.259, p=.018$. Further, the frequency with which children used these terms, $n=83, r=.303, p=.005$, and how accurately they used them, $n=83, r=.335, p=.002$, also correlated with their waiting time. Importantly, these effects held when Age was partialed out (use of temporal terms, $n=$ 83, $r=.242, p=.029$, frequency, $n=83, r=.287, p=.009$, and accuracy, $n=83, r=.322, p=.003$ ) suggesting this effect is not simply due to the fact that older children likely use these terms more frequently and have longer waiting times.

With respect to gender, there was a significant effect of gender on the time children were willing to wait, $F(1,76)=$ $4.825, p=.031$, but no Gender by Time interaction, $F(1,76)=.355, p=.553$, suggesting this effect was consistent across the pre- and post-intervention tests (Table 1). On average, pre-intervention girls waited 8.94 minutes and boys waited 6.42 minutes, with a similar difference post-intervention, where girls waited 9.60 minutes and boys waited 6.15 minutes. To investigate whether this difference was related to children's use of temporal terms, we conducted a series of independentsample t-tests comparing boys and girls across the three time questionnaire measures. Interestingly, compared to boys, girls used significantly more temporal terms, $t(81)=2.912, p=.005, d=.63$, and used them both more frequently, $t(81)=2.636$, $p=.010, d=.58$, and more accurately, $t(81)=2.243, p=.028, d=.49$ (Figure 1 ).

\section{FIGURE 1 ABOUT HERE}

\section{Discussion}


The aim of the current study was to investigate whether 3-year-olds' self-control could be improved by exposing them to a symbolic model demonstrating self-control. It was hypothesised that children would assimilate the behaviour of the patient child in the story book and, as a result, be willing to wait longer for a large reward. Further, it was hypothesised that naming the symbolic model after the child (personal story-telling condition) would have a greater influence on children's wait times than a symbolic model with an unrelated name (impersonal story-telling condition). In contrast to our predictions, neither children in the personal- nor impersonal story-telling condition waited longer at the post-intervention test, and the wait times of children in these two conditions were no different to those of children in the control group. When children who waited the full 15 minutes at the pre-intervention test were excluded, a significant difference was found between pre- and post-intervention tests but this difference was not influenced by condition. It must be acknowledged, however, that excluding the children who waited the 15 minutes at pre-test reduces the statistical power of the analysis and thus we must interpret the absence of an effect of condition with caution. The improvement between the pre- and postintervention tests may be due to a practice effect, with the presentation of the same task at pre- and post-intervention phases resulting in the child being more familiar with the procedure and the task, and thereby enhancing his or her performance (Schmidt \& Teti 2006). Also, during the post-intervention phase children may have (correctly) assumed that the content of the gift box sitting in front of them was the same as during the pre-test session, perhaps making it less tempting to open.

With respect to symbolic models, our story books may not have influenced children's self-control because, being between 2 and 3 years of age, the children in the current study may not yet have developed the conceptual understanding required to assimilate the models' behaviour. That is, although children in the current study could likely understand the story, they may not have understood that the story demonstrated the concept of patience and therefore did not apply this concept to their own behaviour. Sloutsky (2003) suggests that children learn concepts through both perceptual and attentional mechanisms, detecting similarities or discrepancies in the environment and creating categories based on the correspondences they observe. Presenting examples of the concept and contrasting examples helps children detect the important features and facilitates categorization. Concrete concepts (e.g. book, animal, tree) are learnt more easily than abstract concepts (e.g. patience, fairness), because perceptual similarities facilitate the categorization of these objects. Little is known about the development of abstract concepts (Baddeley 1999; Sloutsky 2003). It is possible that young children must be exposed to abstract concepts multiple times in varying contexts to fully understand the meaning of these concepts and to apply them in their everyday life. Further, Simcock and DeLoache (2006) showed that the understanding of the relation between a symbol and what it stands for is in its early stages at 2.5 years, supporting the statement that children in our study may not have benefited from our picture-book, due to their still developing conceptual understanding.

Separate from the concept of patience, our results suggest that children's knowledge of the benefits of waiting (i.e., receiving a bigger present) was not sufficient to keep them from opening the present before the 15 minutes elapsed. This discrepancy between knowledge and behaviour has also been demonstrated on card-sorting tasks where children must switch between sorting rules. Zelazo, Frye, and Rapus (1996) presented children with a set of cards that had coloured shapes on them and had children sort them according to a single rule (e.g., by colour). After learning the first rule, children were taught a new rule and were asked again to sort the cards by this new rule. Interestingly, 3-year-old children expressed knowledge of the new rule, but continued to use the old rule, whereas 4-year-old children displayed no difficulty switching 
between the two rules. Zelazo et al.'s (1996) findings demonstrate that, for children aged 3 years and younger, knowledge is not always sufficient to influence actions. In the current study, it is possible children's knowledge of the benefits of waiting was not sufficient to overcome their prepotent response to open the gift. It is possible that children aged four and older may benefit more from symbolic models in story books than younger children.

In our story-book, both the non-patient and the patient child received a gift from the magical figure, the first receiving a lollipop and the second receiving a toy. Social learning theory suggests that the rewards associated with the modelled behaviour influence the likelihood of the behaviour being imitated (Bandura \& McClelland 1977). It is possible that some children perceived the lollipop as more desirable than the toy and, consequently, displayed similar non-patient behaviour on our laboratory task. To exclude this possibility, it would be interesting to vary the magnitude (e.g., size), rather than the type, of the reward the child receives if they wait. Bandura and McClelland's (1977) theory also recognizes the importance of perceived similarity between the model and the learner, which may have been lacking in our story-book due the stories being more fantasy-based. Placing pictures of actual children in the story book would improve the similarity between the book and the real world and may increase children's self-efficacy (Dowrick 2000).

A serendipitous finding of the current study was the relationship between children's production and accurate use of temporal terms and their ability to wait for the larger reward. That is, the more temporal terms children used and the more accurately they used them, the longer they were willing to wait. This effect held when age was partialed out, suggesting it was not simply due to older children having both a better vocabulary and longer waiting times. Previous studies have shown that children's use of temporal terms begins at around the age of 2 and rapidly grows thereafter. Busby Grant and Suddendorf (2011) suggested that 3-year-olds often and accurately use terms representing the present and broad temporal terms such as 'soon' or 'later'. Specific terms related to the future or the past (e.g. yesterday, tomorrow) are learnt later than general terms (e.g. when I was little), between the age of 3 and 5 years. In our study, girls had a larger temporal vocabulary than boys, and interestingly, also waited longer than boys. Surprisingly, Busby Grant and Suddendorf (2011) did not find gender differences in the use or accuracy of temporal terms.

Consistent with our findings, a recent meta-analysis reported that girls delay gratification for longer periods of time (Silverman 2003). Speculatively, our finding suggests this link may be due to the girls' ability to use temporal terms and that their use of temporal terms may reflect a clearer understanding of the past and future. It is possible that children with a larger temporal vocabulary are better able to project themselves into the future, and are willing to delay gratification to give their future-self a larger reward than what the present-self would receive. It is through conversations about the self in noncurrent situations that children learn about their extended self in time (Moore and Lemmon 2001; Nelson 2001). Between the ages of 2 and 5 children acquire the sense of self as continuous in time, with increasing capacity to talk about different experiences (Nelson 2001), and it is also between these years that children's ability to delay gratification slightly increases (Lemmon \& Moore 2007). To our knowledge, no studies have analysed the relation between knowledge of temporal terms and the ability to sacrifice an immediate reward in favour of a future larger reward. It is possible that the more specific temporal terms children understand and use, the better their understanding of time and the better their representation of the self in time. 
In our study, we did not measure children's general language competence which may also relate to children's ability to delay of gratification. Language impairments are known to correlate with maladaptive outcomes, such as ADHD (Bruce et al. 2006; Cohen et al. 2000), aggressive behaviours (Dionne et al. 2003; Estrem 2005) and poor problem solving (Baldo et al. 2005; Cohen et al. 1998), which are all linked to low self-control. Language skills are thought to enhance children's self-regulatory competence by enabling them to express themselves verbally instead of emotionally, reflect on their behaviour, and occupy themselves in the presence of emotional circumstances (Cole et al. 2010). For example, language may allow children to reflect on rules and shift their attention, rather than focusing on items that they cannot have (Roben et al. 2013). To our knowledge, very few studies have analysed the link between language and self-control. Beaver, DeLisi, Vaughn, Wright, and Boutwell (2008) conducted a longitudinal study from the beginning of kindergarten to the end of first grade over four time points. They discovered that language skills significantly correlated with self-control at the beginning of kindergarten, and this result held over years, showing that higher language competences are associated with higher self-control. In their longitudinal study following children from 18 to 48 months of age over four time points, Cole et al. (2010) analysed how early language development influenced anger expressions and the use of regulatory strategies. They found that language skills and the rate of language growth at 24 and 36 months were a strong predictor of anger expressions at 48 months, with higher language skills being associated with lower anger expressions. Higher language skills were also associated with children's initiation of seeking mothers support at 36 and 48 months, which lead to less angry expressions. Children's language skills were also associated with their ability to distract themselves at 36 and 48 months of age, indicating higher language skills are associated with a higher frustration threshold. These two studies show a significant link between self-control and language competence. Therefore, in the future it would be of interest to study the relationship between children's general language competences, their understanding of time and their ability to delay gratification, to identify how each one contributes to variations in self-control.

With respect to limitations, in the present study we did not assess children's understanding of the theme or message of the story book. Although it is important to note that the book was short, had a simple story line, and was read to children on multiple occasions. It would be beneficial in future studies to assess children's understanding of the book, perhaps by using the story book as a prop and asking children to show and tell the experimenter what happens in the book. Previous studies have demonstrated that this show and tell technique is effective with young children (Hayne \& Imuta 2011; Scarf et al. 2013). A second limitation is that parents, and often siblings, were in the experimental room during the delay-ofgratification task. This may have influenced the children's behaviour, by distracting them or by giving implicit signals to not open the present (e.g. movements of the head, moving when the child reached for the gift) (Bandura 1992; Putnam et al. 2002). Finally, parents may have coached their child between the pre- and post-intervention tests. For example, one parent noted they tried to train their child on a delay-of- gratification task at home and thoroughly discussed the behaviours described in the book.

In summary, the present suggests 3-year-old children do not assimilate a behaviour modelled in a story-book into their own behaviour. Between pre-school and primary school, children's language ability and conceptual understanding increases dramatically and, therefore, symbolic models may be more effective for children slightly older than those used in the present experiment. The positive relationship observed between children's temporal vocabulary and their ability to delay 
337 gratification suggests a larger temporal vocabulary may be linked to children's understanding of the future and the past and 338 this may make it easier for children to envisage the self in the future receiving the large reward, making the small reward 339 less tempting. Future studies may look to investigate the possible relationship between the ability to delay gratification and 340 children's perception of the extended self in time.

\section{Ethical Standards} of participants gave their informed consent before the children were included in the study. 
Ayduk O, Rodriguez ML, Mischel W, Shoda Y, and Wright J. 2007. Verbal intelligence and self-regulatory competencies: Joint predictors of boys' aggression. Journal of Research in Personality 41:374-388.

Baddeley AD. 1999. Essentials of human memory: Psychology Press.

Baldo JV, Dronkers NF, Wilkins D, Ludy C, Raskin P, and Kim J. 2005. Is problem solving dependent on language? Brain and language 92:240-250.

Bandura A. 1965. Influence of models' reinforcement contingencies on the acquisition of imitative responses. Journal of Personality and Social Psychology 1:589-595.

Bandura A. 1992. Social cognitive theory of social referencing. In: Feinman S, ed. Social referencing and the social construction of reality in infancy. New York: Plenum Press, 175-208.

Bandura A, and McClelland DC. 1977. Social learning theory. Engelwood Cliffs, NJ: Prentice Hall.

Bandura A, and Mischel W. 1965. Modifications of self-imposed delay of reward through exposure to live and symbolic models. Journal of Personality and Social Psychology 2:698-705.

Beaver KM, DeLisi M, Vaughn MG, Wright JP, and Boutwell BB. 2008. The relationship between self-control and language: evidence of a shared etiological pathway*. Criminology 46:939-970.

Bruce B, Thernlund G, and Nettelbladt U. 2006. ADHD and language impairment. European child \& adolescent psychiatry 15:52-60.

Busby Grant J, and Suddendorf T. 2011. Production of temporal terms by 3-, 4-, and 5-year-old children. Early Childhood Research Quarterly 26:87-95.

Casey B, Somerville LH, Gotlib IH, Ayduk O, Franklin NT, Askren MK, Jonides J, Berman MG, Wilson NL, and Teslovich T. 2011. Behavioral and neural correlates of delay of gratification 40 years later. Proceedings of the National Academy of Sciences 108:14998-15003.

Cohen NJ, Menna R, Vallance DD, Barwick MA, Im N, and Horodezky NB. 1998. Language, social cognitive processing, and behavioral characteristics of psychiatrically disturbed children with previously identified and unsuspected language impairments. Journal of Child Psychology and Psychiatry 39:853-864.

Cohen NJ, Vallance DD, Barwick M, Im N, Menna R, Horodezky NB, and Isaacson L. 2000. The interface between ADHD and language impairment: An examination of language, achievement, and cognitive processing. Journal of Child Psychology and Psychiatry 41:353-362.

Cole PM, Armstrong LM, and Pemberton CK. 2010. The role of language in the development of emotion regulation. In: Calkins SD, and Bell MA, eds. Child developement at the intersection of emotion and cognition. Washington, DC: American Psychological Association, 59-77.

de Droog SM, Buijzen M, and Valkenburg PM. 2014. Enhancing children's vegetable consumption using vegetablepromoting picture books. The impact of interactive shared reading and character-product congruence. Appetite 73:73-80.

Dionne G, Tremblay R, Boivin M, Laplante D, and Perusse D. 2003. Physical aggression and expressive vocabulary in 19month-old twins. Developmental Psychology 39:261-273.

Dowrick PW. 2000. A review of self modeling and related interventions. Applied and Preventive Psychology 8:23-39.

Estrem TL. 2005. Relational and physical aggression among preschoolers: The effect of language skills and gender. Early Education \& Development 16:207-232.

Ganea PA, Pickard MB, and DeLoache JS. 2008. Transfer between picture books and the real world by very young children. Journal of cognition and development 9:46-66.

Gelfand DM. 1962. The influence of self-esteem on rate of verbal conditioning and social matching behavior. Journal of Abnormal and Social Psychology 65:259-265.

Hayne H, and Imuta K. 2011. Episodic memory in 3- and 4-year-old children. Developmental Psychobiology 53:317-322.

Heath P, Houston-Price C, and Kennedy OB. 2014. Let's look at leeks! Picture books increase toddlers' willingness to look at, taste and consume unfamiliar vegetables. Frontiers in Psychology 5:191.

Lee P-L, Lan W, Wang C-L, and Chiu H-Y. 2008. Helping young children to delay gratification. Early Childhood Education Journal 35:557-564.

Lemmon K, and Moore C. 2007. The development of prudence in the face of varying future rewards. Developmental Science 10:502-511.

Li-Grining CP. 2007. Effortful control among low-income preschoolers in three cities: Stability, change, and individual differences. Developmental Psychology 43:208-221. 
400

401

402

403

404

405

406

407

408

409

410

411

412

413

414

415

416

417

418

419

420

421

422

423

424

425

426

427

428

429

430

431

432

433

434

435

436

437

438

439

440

441

442

443

444

445

446

447

448

449

450

451

452

453

Madden GJ, Petry NM, Badger GJ, and Bickel WK. 1997. Impulsive and self-control choices in opioid-dependent patients and non-drug-using control patients: Drug and monetary rewards. Experimental and Clinical Psychopharmacology 5:256-262.

Mauro CF, and Harris YR. 2000. The influence of maternal child-rearing attitudes and teaching behaviors on preschoolers' delay of gratification. The Journal of genetic psychology 161:292-306.

McIntyre LL, Blacher J, and Baker B. 2006. The transition to school: Adaptation in young children with and without intellectual disability. Journal of Intellectual Disability Research 50:349-361.

Meichenbaum DH. 1971. Examination of model characteristics in reducing avoidance behavior. Journal of Personality and Social Psychology 17:298-307.

Metcalfe J, and Mischel W. 1999. A hot/cool-system analysis of delay of gratification: dynamics of willpower. Psychological Review 106:3.

Mischel W. 2014. The marshmallow test: Mastering self-control. New York: Hachette Book Group, Inc.

Mischel W, Shoda Y, and Peake PK. 1988. The nature of adolescent competencies predicted by preschool delay of gratification. Journal of Personality and Social Psychology 54:687-696.

Mischel W, Shoda Y, and Rodriguez M. 1989. Delay of Gratification in Children. Science 244:933-938.

Mischel W, and Underwood B. 1974. Instrumental ideation in delay of gratification. Child development 45:1083-1088.

Moffitt TE, Arseneault L, Belsky D, Dickson N, Hancox RJ, Harrington H, Houts R, Poulton R, Roberts BW, and Ross S. 2011. A gradient of childhood self-control predicts health, wealth, and public safety. Proceedings of the National Academy of Sciences 108:2693-2698.

Nelson K. 2001. Language and the self: From the" Experiencing I" to the" Continuing Me". In: Moore C, Lemmon K, and Skene K, eds. The self in time: Developmental perspectives. Hillsdale, NJ: Lawrence Erlbaum Associates Inc.

Putnam SP, Spritz BL, and Stifter CA. 2002. Mother-Child Coregulation During Delay of Gratification at 30 Months. Infancy 3:209-225.

Roben CK, Cole PM, and Armstrong LM. 2013. Longitudinal relations among language skills, anger expression, and regulatory strategies in early childhood. Child development 84:891-905.

Scarf D, Gross J, Colombo M, and Hayne H. 2013. To have and to hold: Episodic memory in 3- and 4-year-old children. Developmental Psychobiology 55:125-132.

Schlam TR, Wilson NL, Shoda Y, Mischel W, and Ayduk O. 2013. Preschoolers' delay of gratification predicts their body mass 30 years later. The Journal of pediatrics 162:90-93.

Schmidt KRT, and Teti DM. 2006. Issues in the use of longitudinal and cross-sectional designs. In: Teti DM, ed. Handbook of research methods in developmental science. Malden, MA: Blackwell, 3-20.

Schunk DH. 1987. Peer models and children's behavioral change. Review of educational research 57:149-174.

Sethi A, Mischel W, Aber JL, Shoda Y, and Rodriguez ML. 2000. The role of strategic attention deployment in development of self-regulation: Predicting preschoolers' delay of gratification from mother-toddler interactions. Developmental Psychology 36:767.

Shoda Y, Mischel W, and Peake PK. 1990. Predicting adolescent cognitive and self-regulatory competencies from preschool delay of gratification: Identifying diagnostic conditions. Developmental Psychology 26:978-986.

Silverman IW. 2003. Gender differences in delay of gratification: A meta-analysis. Sex roles 49:451-463.

Simcock G, and DeLoache J. 2006. Get the picture? The effects of iconicity on toddlers' reenactment from picture books. Developmental Psychology 42:1352-1357.

Sloutsky VM. 2003. The role of similarity in the development of categorization. Trends in Cognitive Sciences 7:246-251.

Strayhorn Jr JM. 1988. The competent child: An approach to psychotherapy and preventive mental health. New York: Guilford Press.

Strayhorn Jr JM. 2002. Self-control: Theory and research. Journal of the American Academy of Child \& Adolescent Psychiatry 41:7-16.

Suprawati M, Anggoro FK, and Bukatko D. 2014. "I think I can": achievement-oriented themes in storybooks from Indonesia, Japan, and the United States. Frontiers in Psychology 5:167.

Tare M, Chiong C, Ganea P, and DeLoache J. 2010. Less is more: How manipulative features affect children's learning from picture books. Journal of applied developmental psychology 31:395-400.

Wulfert E, Block JA, Santa Ana E, Rodriguez ML, and Colsman M. 2002. Delay of gratification: Impulsive choices and problem behaviors in early and late adolescence. Journal of personality 70:533-552.

Zelazo PD, Frye D, and Rapus T. 1996. An age-related dissociation between knowing rules and using them. Cognitive Development 11:37-63.

PeerJ reviewing PDF | (v2014:12:3614:1:1:NEW 25 Jan 2015) 
454

455

PeerJ reviewing PDF | (v2014:12:3614:1:1:NEW 25 Jan 2015) 
1

Questionair and behavoural measures

Differences between girls and boys in (a) the use of temporal terms; (b) the frequency with which they use temporal terms; (c) the accuracy of use of temporal terms; (d) the amount of time they were willing to wait across pre- and post-intervention. The error bars represent the standard error of the mean.

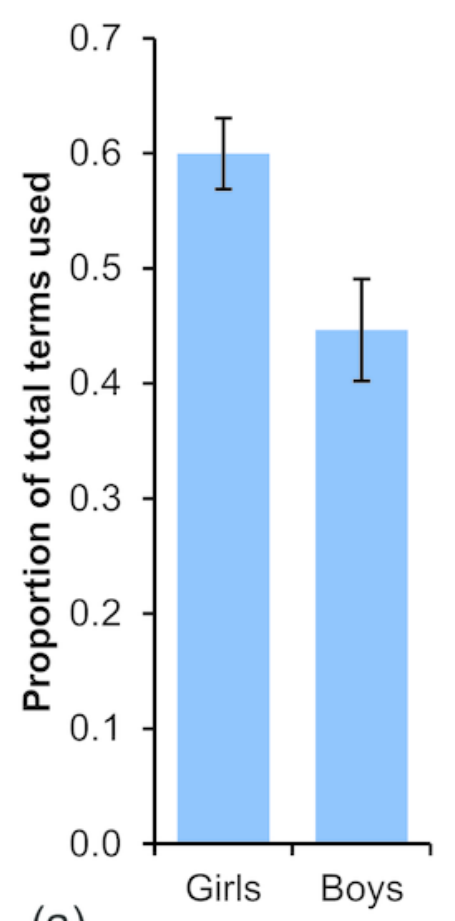

(a)

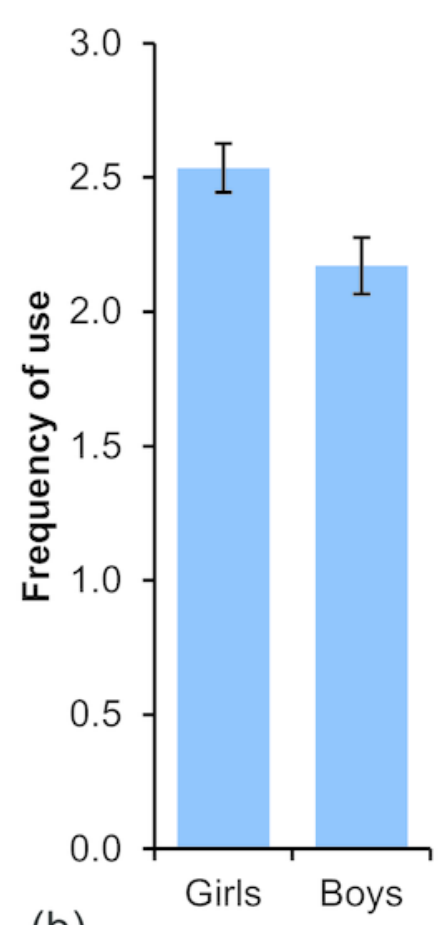

(b)

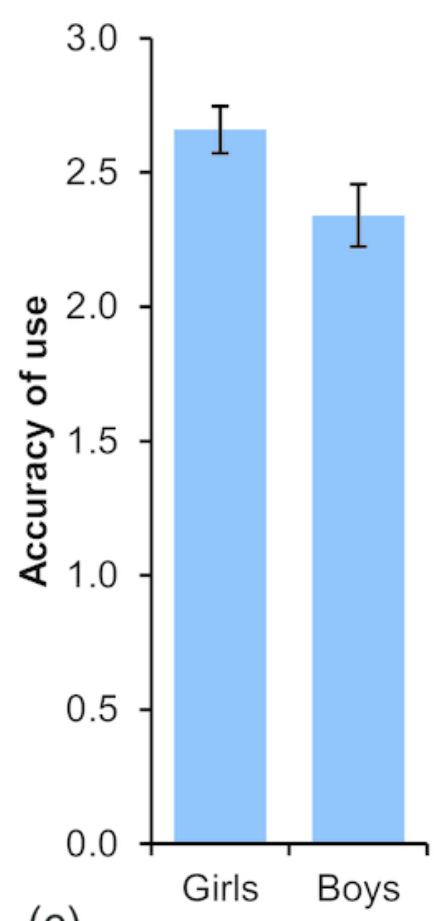

(c)

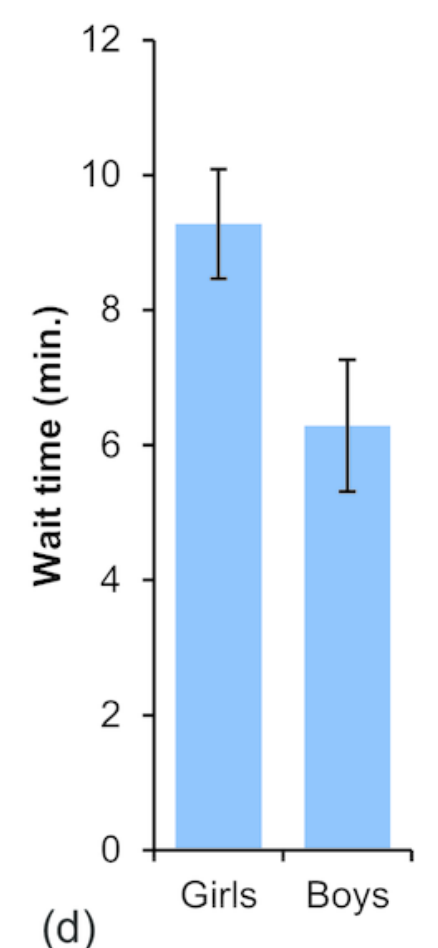

(d) 


\section{Table $\mathbf{1}$ (on next page)}

The performance of all children on the delay-of-gratification task.

The performance of all children in the personal story, simple story, and control story conditions. 


\begin{tabular}{|c|c|c|c|c|c|}
\hline Group & Personal & Impersonal & Control & Boys & Girls \\
\hline \multicolumn{6}{|l|}{ Pre-test } \\
\hline Mean & 7.94 & 7.18 & 8.29 & 6.42 & 8.94 \\
\hline SD & 5.94 & 6.78 & 6.39 & 5.93 & 6.46 \\
\hline $\mathrm{N}$ (boy/girl) & $27(12 / 15)$ & $27(12 / 15)$ & $29(13 / 16)$ & 37 & 46 \\
\hline \multicolumn{6}{|l|}{ Post-test } \\
\hline Mean & 8.21 & 8.03 & 7.96 & 6.15 & 9.60 \\
\hline SD & 6.64 & 6.94 & 6.71 & 6.71 & 6.32 \\
\hline N (boy/girl) & $27(12 / 15)$ & $27(12 / 15)$ & $29(13 / 16)$ & 37 & 46 \\
\hline
\end{tabular}

2 
Table 2 (on next page)

The performance of children that did not wait the full 15 minutes pre-intervention

The performance of children in the personal story, simple story, and control story condtions that did not wait the full 15 minutes at the pre-intervention test. 


\begin{tabular}{llllll}
\hline Group & Personal & Impersonal & Control & Boys & Girls \\
\hline Pre-test & & & & & \\
\hline Mean & 4.97 & 2.58 & 3.55 & 4.05 & 3.38 \\
SD & 4.42 & 3.76 & 3.74 & 4.28 & 3.81 \\
N (boy/girl) & $19(10 / 9)$ & $17(9 / 8)$ & $17(10 / 7)$ & 29 & 24 \\
\hline Post-test & & & & 4.15 & 6.70 \\
\hline Mean & 6.11 & 5.42 & 4.29 & 5.79 & 6.47 \\
SD & 6.16 & 6.74 & 5.86 & 29 & 24 \\
N (boy/girl) & $19(10 / 9)$ & $17(9 / 8)$ & $17(10 / 7)$ & 29 & \\
\hline
\end{tabular}

2 